\title{
Randomized study of adjunctive belimumab in participants with generalized myasthenia gravis
}

\author{
Karen Hewett, PhD, Donald B. Sanders, MD, Richard A. Grove, MSc, Christine L. Broderick, BS, \\ Todd J. Rudo, MD, Ashlyn Bassiri, PhD, Marina Zvartau-Hind, MD, and Vera Bril, MD, On behalf of the \\ BEL115123 Study Group
}

Neurology ${ }^{\circledR}$ 2018;90:e1425-e1434. doi:10.1212/WNL.0000000000005323

\section{Correspondence}

Prof. Bril

vera.bril@utoronto.ca

\section{MORE ONLINE}

$\rightarrow$ Class of Evidence

Criteria for rating

therapeutic and diagnostic studies

NPub.org/coe

\section{Methods}

Eligible participants with MG were randomized 1:1 to receive IV belimumab $10 \mathrm{mg} / \mathrm{kg}$ or placebo in this phase II, placebo-controlled, multicenter, double-blind study (NCT01480596; BEL115123). Participants received SoC therapies throughout the 24-week treatment phase and 12-week follow-up period. The primary efficacy endpoint was mean change from baseline in the Quantitative Myasthenia Gravis (QMG) scale at week 24; safety assessments included the frequency and severity of adverse events (AEs) and serious AEs.

\section{Results}

Forty participants were randomized (placebo $n=22$; belimumab $n=18$ ). The mean change in QMG score from baseline at week 24 was not significantly different for belimumab vs placebo $(p=0.256)$. There were no statistically significant differences between treatment groups for secondary endpoints, including the MG Composite and MG-Activity of Daily Living scores. Acetylcholine receptor antibody levels decreased over time in both treatment groups. No unexpected AEs were identified and occurrence was similar in the belimumab (78\%) and placebo (91\%) groups. One participant receiving placebo died (severe sepsis) during the treatment phase.

\section{Conclusions}

The primary endpoint was not met for belimumab in participants with generalized MG receiving SoC. There was no significant difference in mean change in the QMG score at week 24 for belimumab vs placebo. The safety profile of belimumab was consistent with previous systemic lupus erythematosus studies.

\section{Classification of evidence}

This study provides Class I evidence that for participants with generalized MG, belimumab did not significantly improve QMG score compared with placebo. 


\section{Glossary}

AChR $=$ acetylcholine receptor; $\mathbf{A E}=$ adverse event; AESI $=$ adverse events of special interest; $\mathbf{B L y S}=\mathrm{B}$-lymphocyte stimulator; Ig = immunoglobulin; ITT = intention-to-treat; LOCF = last observation carried forward; MG = myasthenia gravis; MG-ADL = Myasthenia Gravis Activities of Daily Living; MGC = Myasthenia Gravis Composite; MGFA = Myasthenia Gravis Foundation of America; MMRM = mixed model for repeated measures; MuSK = muscle-specific tyrosine kinase; PLEX = plasma exchange; PP = per protocol; $\mathbf{Q M G}=$ Quantitative Myasthenia Gravis; SAE = serious adverse events; SLE = systemic lupus erythematosus; SoC $=$ standard of care.

Myasthenia gravis (MG), an acquired autoimmune disorder of neuromuscular transmission, affects over 700,000 people worldwide. $^{1,2}$ Approximately $85 \%$ of generalized MG cases are associated with postsynaptic nicotinic acetylcholine receptor (AChR) antibodies at the motor endplate ${ }^{1,3}$ and reduced functional AChRs. ${ }^{1}$ Approximately $5 \%-8 \%$ of patients have muscle-specific tyrosine kinase (MuSK) antibodies. ${ }^{4}$ Lipoprotein receptor-related protein 4 antibodies may also be clinically relevant. ${ }^{5,6}$

Numerous (predominantly off-label) treatments are prescribed for MG, as summarized in a recent international consensus guidance statement for MG treatment by a Task Force of the Myasthenia Gravis Foundation of America. ${ }^{2}$ Many patients do not achieve adequate clinical response, having substantial disability despite treatment. ${ }^{7}$ Developing a therapy suitable for all patients is challenging due to disease heterogeneity. ${ }^{2}$ Acetylcholinesterase inhibitors (e.g., pyridostigmine) are considered first-line treatments for $M G$; however, patients with anti-MuSK antibodies often respond poorly. ${ }^{1,8}$ Glucocorticoids or nonsteroidal immunosuppressant therapy are recommended in patients failing to meet treatment goals following an adequate pyridostigmine trial. $^{2}$

Belimumab (Benlysta, Rockville, MD), a human immunoglobulin (Ig) G1 $\lambda$ monoclonal antibody against B-lymphocyte stimulator (BLyS), is licensed for adult patients with active, autoantibody-positive systemic lupus erythematosus (SLE) receiving standard SLE therapy. ${ }^{9,10}$ Elevated BLyS levels have been identified in patients with $\mathrm{MG}^{11-13}$ highlighting it as a potential treatment target. Other monoclonal antibodies (e.g., rituximab and eculizumab) targeting different immune elements have demonstrated promising results. ${ }^{14-17}$

This study investigated the efficacy and safety of belimumab in participants with active generalized MG despite receiving standard therapy.

\section{Methods}

\section{Study design}

This phase II, randomized, placebo-controlled, double-blind study (BEL115123) was conducted at 13 centers in Canada, United States, Germany, and Italy between April 2013 and October 2015. Randomization was performed centrally using a computer-generated randomization schedule, created by the study statistician, stratified by antibody status. Randomization numbers were allocated to participants by an interactive voice recognition system. Blinding was maintained throughout the study until the final on-treatment assessment (week 24) for the final participant had been completed, entered into the database, and the initial database lock had been performed for the primary analysis. While the follow-up section of the study was ongoing, the results of the primary analysis were made available only to a limited group of sponsor personnel; neither the study participants nor the study site personnel were aware of results or of the treatment received. All GSK local operating companies, monitors, and investigators remained blinded until completion of the final analysis at the end of the followup phase (week 36). Eligible participants were randomized $1: 1$ to receive either IV belimumab $10 \mathrm{mg} / \mathrm{kg}$ or placebo (weeks $0,2,4,8,12,16$, and 20), and were stratified by antibody screening (AChR/MuSK). Participants were maintained on standard of care $(\mathrm{SoC})$ therapies throughout. The treatment regimen was selected according to the results of 2 pivotal phase III SLE studies (BLISS-52, NCT00424476 and BLISS-76, NCT00410384). ${ }^{18,19}$ Belimumab $10 \mathrm{mg} / \mathrm{kg}$, administered IV, resulted in a statistically significant (BLISS-52) and numerically greater (BLISS-76) improvement in the primary efficacy endpoint (SLE Responder Index) compared with placebo by week $24 .{ }^{18,19}$ Consequently, a 4 -week screening period, 24-week treatment period, and 12-week follow-up period (during which no investigational treatment was administered) was employed for this study.

\section{Standard protocol approvals, registrations, and participant consents}

This study (clinicaltrials.gov identifier NCT01480596) was performed in accordance with the International Conference for Harmonisation of Technical Requirements for Pharmaceuticals for Human Use, Good Clinical Practice guidelines, the ethical procedures outlined in the Declaration of Helsinki, ${ }^{20}$ and applicable country-specific requirements. Written informed consent was obtained from each participant prior to any study-specific procedures.

\section{Participants}

\section{Inclusion criteria}

Eligible participants had generalized MG (Myasthenia Gravis Foundation of America [MGFA] Class II-IVa inclusive), ${ }^{21}$ 
were $\geq 18$ years of age, were positive for AChR/MuSK antibodies, and had a Quantitative MG (QMG) score ${ }^{22}$ of $\geq 8$, of which $\geq 4$ points were derived from signs other than ocular. At entry to the study, participants must have been receiving a stable dose of one or more of the following MG treatments ${ }^{1}$ : a cholinesterase inhibitor for a minimum of 2 weeks prior to screening and/or ${ }^{2}$ prednisone (minimum 1 month) and/or ${ }^{3}$ one of the following immunosuppressants: cyclosporine (minimum 3 months), methotrexate (minimum 3 months), azathioprine (minimum 6 months), or mycophenolate (minimum 6 months). Female participants were eligible for enrollment provided they were of nonchildbearing potential or of childbearing potential and not pregnant or nursing and agreed to several predefined criteria designed to prevent pregnancy from enrollment to 16 weeks post last dose of study treatment.

\section{Exclusion criteria}

Key exclusion criteria included presence or history of thymoma, thymectomy within 12 months, and treatment with IV immunoglobulin (Ig) or plasma exchange (PLEX) within 4 weeks prior to screening or potential requirement for these treatments during the study. Participants were excluded if they had received treatment with rituximab or eculizumab within 12 months of screening, or with any other B celltargeted therapy (including belimumab) at any time; treatment with any immunosuppressive agent other than those permitted within the inclusion criteria within 6 months; or a history of recurrent or chronic infection or currently active systemic infection.

\section{Objectives}

The primary objective of this study was to investigate the efficacy of belimumab vs placebo in reducing signs of $\mathrm{MG}$, measured by QMG score, in participants who remained symptomatic (defined by QMG score) on SoC therapy. Secondary objectives included additional efficacy assessments, safety, and tolerability; modulation of AChR/MuSK antibody levels; and pharmacodynamic/biomarker assays. This study aimed to provide Class I evidence for the efficacy and safety of belimumab in participants with MG.

\section{Endpoints}

\section{Efficacy endpoints}

The primary endpoint was mean change from baseline in QMG score at week 24 compared with baseline. Secondary efficacy endpoints were mean change from baseline in the MG Composite Score (MGC) ${ }^{23}$ at week 24 and mean change from baseline in the Myasthenia Gravis Activities of Daily Living (MG-ADL) scale ${ }^{24}$ at weeks 12 and 24. The proportion of participants with $\geq 3$-point QMG/MGC improvement or worsening from baseline by week 24 and with a sustained improvement of $\geq 3$ points from baseline at week 12 maintained to week 24 were also analyzed. Mean changes from baseline in QMG, MGC, and MG-ADL scores were assessed during the follow-up period at weeks 28, 32, and 36. The MGFA postintervention status, ${ }^{21}$ despite being a secondary efficacy endpoint, was not analyzed due to inconsistent data collection across sites.

\section{Safety endpoints}

Safety endpoints (treatment and follow-up phases) included the frequency and severity of adverse events (AEs), serious AEs (SAEs), the percentage of participants with drug-related AEs, and those withdrawing due to AEs. Predefined AEs of special interest (AESI) included malignancies, hypersensitivity and infusion reactions, opportunistic infections, and suicidality. Changes from baseline, proportion of participants with values of potential clinical concern (vital signs, hematology and clinical chemistry parameters), and incidence of antibelimumab immunogenicity were assessed.

\section{Pharmacodynamic/biomarker endpoints}

Change from baseline in $\mathrm{AChR} / \mathrm{MuSK}$ antibody titers and in B- and T-cell counts were analyzed at weeks 8, 24, 28, and 36.

\section{Pharmacokinetic endpoints}

Serum concentrations of belimumab were measured at day 0 and weeks $2,8,20,24$, and 28 .

\section{Statistical analyses}

The estimated sample size was 42 participants to obtain completion of at least one postbaseline efficacy assessment by a minimum of 38 participants, providing at least $80 \%$ power to detect a treatment difference of 4.0 for the primary endpoint, assuming a SD of 4.25 utilizing $t$ test methodology.

The safety population comprised all participants who had at least one infusion of the study agent. The intention-to-treat (ITT) population included all participants in the safety population who had any posttreatment efficacy assessment; this was the primary efficacy analysis population. The per protocol (PP) population was a subset of the ITT population who were not major protocol violators. The PP population was used as a sensitivity analysis, including analysis of variance on last observation carried forward (LOCF) values, for the primary endpoint only.

Change from baseline in QMG score at week 24 was analyzed using a mixed model for repeated measures (MMRM), adjusting for treatment group, visit, baseline QMG score, visit by treatment group interaction, and visit by baseline QMG score interaction. The MMRM models fitted participants as a random effect and used an unstructured covariance matrix. ${ }^{25}$ Given the exploratory nature of the study, Bayesian interpretation for the MMRM analysis of QMG and MGC assuming noninformative priors was also generated, and posterior probabilities that the treatment difference was $>0$ were derived. A significant $p$ value from a frequentist 2 -sided test at the $5 \%$ level $(p<0.05)$ is equivalent to the posterior probability exceeding 0.975 (i.e., statistical significance occurs at the $\alpha \%$ level for a 2 -sided test with no multiplicity adjustment when the PP exceeds $1-([\alpha / 100] / 2){ }^{26}$

Secondary efficacy analyses of continuous data were performed using similar MMRM methods as the primary 
analysis. Analyses comparing the proportion of participants were planned for Cochran-Mantel-Haenszel $\chi^{2}$ analyses using the observed data, where missing data were assumed to be a negative response. Due to very low response rates, proportions of participants improving or worsening were analyzed using exact methodology with tests stratified by the observed median baseline score ( $\leq$ median, $>$ median $)$.

\section{Results}

\section{Study population and participant disposition}

Forty participants were randomized (belimumab $\mathrm{n}=18$; placebo $\mathrm{n}=22$ ) (figure 1). Demographic characteristics and baseline medical and MG history were balanced between the treatment groups. Baseline MG severity, measured by $\mathrm{QMG}$, $\mathrm{MGC}$, and MG-ADL, were in the mild to moderate range; median QMG scores (range) were $12.00(8.0,19.5)$ and 12.50 $(6.50,23.0)$ for belimumab and placebo, respectively (table 1). Participants were predominantly female (62\%) with a mean (SD) age of 56.1 (15.67) years, and a mean (SD) MG symptom duration of 9.0 (8.13) (placebo) or 8.7 (9.00) (belimumab) years. Most participants had AChR antibodies; 2 participants, both in the placebo group, had MuSK antibodies.

\section{Efficacy}

The primary endpoint, QMG mean change (standard error) from baseline at week 24, was -4.21 (1.14) compared with -2.37 (1.10) for placebo (figure 2A). However, the treatment difference (1.84 points) was not statistically significant ( $p=$ 0.256) (table 2). Nevertheless, posterior probability analysis did indicate a signal of potential efficacy (posterior probability $>0.8$ ). Further comparisons of belimumab vs placebo were made for QMG mean change from baseline at week 24 to assess the sensitivity of the analyses to the effects of protocol violations and missing data. These analyses (PP population and LOCF) also demonstrated no significant difference between belimumab and placebo $(p=0.267$ and 0.187 , respectively) (table 2). A change of $\geq 3$ points in QMG score was seen in $61 \%$ of belimumab participants vs $29 \%$ of placebo participants $(p=0.082)$, while only $44 \%$ vs $24 \%$, respectively $(p=0.184)$, demonstrated a sustained change of $\geq 3$ points.

There was no difference between the 2 treatment groups for the mean change from baseline in MGC or MG-ADL score at week 24 or at week 36; the MGC and MG-ADL scores decreased by a similar amount in both groups (figure 2, B and C). The proportion of participants improving by $\geq 3$ points in MGC score was similar in both placebo (48\%) and belimumab (50\%) groups. A greater proportion of belimumab (39\%) than placebo (19\%) participants had a sustained improvement; this was not statistically significant $(p=0.175)$. Slightly more participants worsened ( $\geq 3$ points) in placebo vs belimumab ( $24 \%$ vs $11 \%$, respectively; $p=0.530)$.

\section{Safety}

A similar proportion of participants reported AEs in the belimumab (78\%) and placebo (91\%) groups during the treatment phase (table 3 ). The most common were influenza and nausea (belimumab group) and diarrhea, back pain, and headache (placebo group). Treatment-related AEs were similar across groups: $32 \%$ (placebo) and 28\% (belimumab). Five SAEs (nephrolithiasis, sepsis, ruptured aortic dissection, MG exacerbation, and cholelithiasis) were reported in 4 (18\%) participants in the placebo group only. The MG exacerbation was treated with PLEX; this participant was withdrawn from the study. Severe AEs occurred in 5 (23\%)

Figure 1 CONSORT diagram

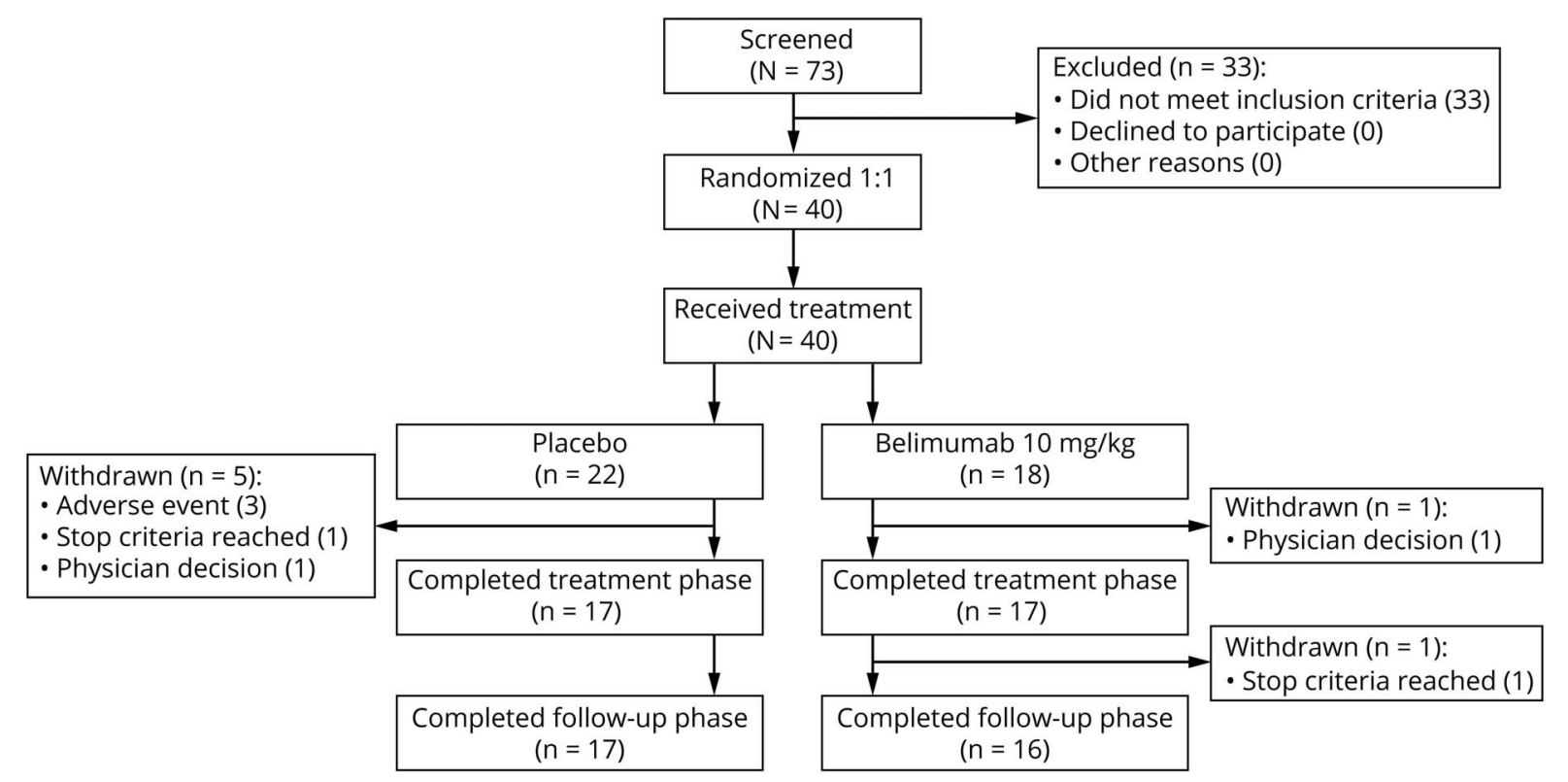


Table 1 Demographic baseline characteristics, myasthenia gravis (MG) history, baseline MG disease, and concomitant MG medications taken during the treatment phase (intention-to-treat population)

\begin{tabular}{|c|c|c|}
\hline & Placebo $(n=21)$ & Belimumab $10 \mathrm{mg} / \mathrm{kg}(\mathrm{n}=18)$ \\
\hline Age, $y$, mean (SD) & $59.0(13.88)$ & $52.7(17.32)$ \\
\hline Female, n (\%) & $14(67)$ & $10(56)$ \\
\hline \multicolumn{3}{|l|}{ MGFA clinical classification, $\mathbf{n}(\%)$} \\
\hline Class IIA & $14(67)$ & $11(61)$ \\
\hline Class IIB & $1(5)$ & $5(28)$ \\
\hline Class IIIA & $4(19)$ & $2(11)$ \\
\hline Class IIIB & $2(10)$ & 0 \\
\hline \multicolumn{3}{|l|}{ MG diagnosis duration, $y$} \\
\hline Mean (SD) & $8.30(8.06)$ & $6.95(9.03)$ \\
\hline Median (min, max) & $6.64(0.8,29.3)$ & $3.47(0.2,37.5)$ \\
\hline \multicolumn{3}{|l|}{ MG symptom duration, $y$} \\
\hline Mean (SD) & $9.01(8.13)$ & $8.68(9.00)$ \\
\hline Median (min, max) & $7.26(1.5,29.9)$ & $6.26(0.8,37.5)$ \\
\hline Myasthenic crisis since MG diagnosis, $\mathrm{n}(\%)$ & $4(19)$ & $4(22)$ \\
\hline Thymectomy, n (\%) & $7(33)$ & $6(33)$ \\
\hline QMG median score (range) & $12.50(6.50,23.0)$ & $12.00(8.0,19.5)$ \\
\hline MGC median score (range) & $12.00(2.00,28.0)$ & $11.50(7.0,20.0)$ \\
\hline MG-ADL median score (range) & $5.00(0,13.0)$ & $5.50(1.0,11.0)$ \\
\hline Any concomitant MG medications, $n(\%)$ & $22(100)$ & $18(100)$ \\
\hline Cholinesterase inhibitor & $21(95)$ & $14(78)$ \\
\hline Pyridostigmine bromide & $16(73)$ & $14(78)$ \\
\hline Pyridostigmine & $6(27)$ & 0 \\
\hline Steroid & $19(86)$ & $13(72)$ \\
\hline Prednisone $^{a}$ & $18(82)$ & $13(72)$ \\
\hline Methylprednisolone sodium succinate ${ }^{b}$ & $1(5)$ & 0 \\
\hline Immunosuppressant & $11(50)$ & $8(44)$ \\
\hline Azathioprine & $5(23)$ & $5(28)$ \\
\hline Mycophenolic acid & $3(14)$ & $2(11)$ \\
\hline Cyclosporine & $1(5)$ & 0 \\
\hline Methotrexate & 0 & $1(6)$ \\
\hline Mycophenolate mofetil & $1(5)$ & 0 \\
\hline Mycophenolate sodium & $1(5)$ & 0 \\
\hline Other MG medication & $1(5)$ & 0 \\
\hline PLEX & $1(5)$ & 0 \\
\hline
\end{tabular}

Abbreviations: MG-ADL = Myasthenia Gravis Activities of Daily Living; MGC = Myasthenia Gravis Composite; MGFA = Myasthenia Gravis Foundation of America; PLEX = plasma exchange; QMG = Quantitative Myasthenia Gravis.

${ }^{\text {a }}$ The median average daily dose of prednisone was $15 \mathrm{mg}$ (range $2.5-50 \mathrm{mg}$ ).

${ }^{\mathrm{b}}$ One participant received a single dose of methylprednisolone sodium succinate prior to surgery in order to minimize any stress-induced exacerbation. 
Figure 2 Adjusted mean change from baseline in Quantitative Myasthenia Gravis (QMG), Myasthenia Gravis Composite (MGC), and Myasthenia Gravis Activities of Daily Living (MG-ADL) (mixed model for repeated measures [MMRM])
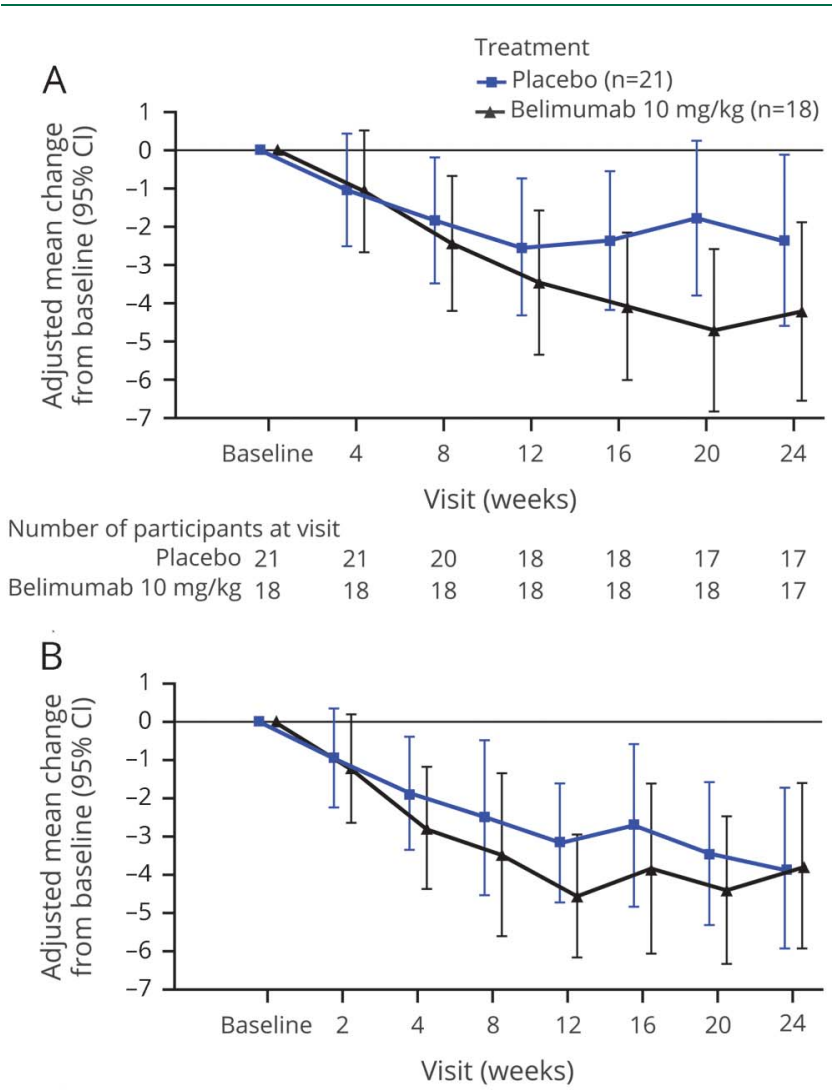

\begin{tabular}{rllllllll} 
Number of participants at visit & \multicolumn{1}{l}{ Placebo 21} & 21 & 21 & 20 & 19 & 19 & 18 & 17 \\
Belimumab $10 \mathrm{mg} / \mathrm{kg}$ & 18 & 18 & 18 & 18 & 18 & 18 & 18 & 17
\end{tabular}

C

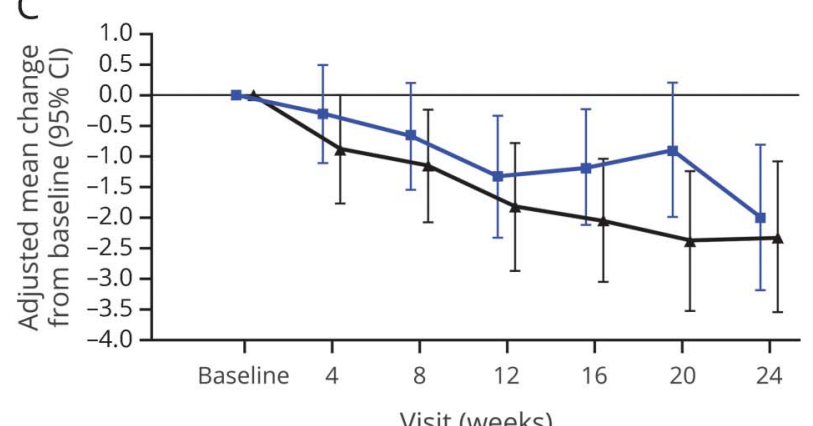

Number of participants at visit

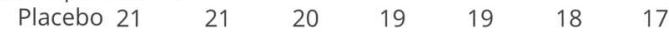

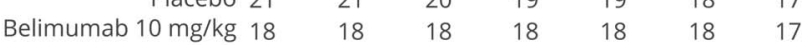

(A) QMG. (B) MGC. (C) MG-ADL (MMRM). Data represent the intention-totreat (ITT) population. Negative score is indicative of an improvement. The MMRM analysis method was adjusted for treatment and visit baseline scale score, treatment by visit, and baseline scale score by visit. The QMG score at baseline is the average of the screening and week 0 baseline scores. The MGC and MG-ADL score at baseline was the week 0 baseline score. $\mathrm{Cl}=$ confidence interval.

participants receiving placebo and $1(6 \%)$ participant in the belimumab group. One participant receiving placebo died due to severe sepsis; concomitant medications for this participant included azathioprine. Twelve participants in the placebo (55\%) and belimumab (67\%) groups experienced AEs during the follow-up phase, with severe AEs reported in 1 (5\%) participant receiving placebo and $3(17 \%)$ participants receiving belimumab. Three participants (placebo group) had AEs that led to withdrawal from the study; all were classified as SAEs. No deaths occurred during follow-up.

AESI were reported in $5(23 \%)$ and $4(22 \%)$ participants (treatment phase) in the placebo and belimumab groups, respectively; the most common events were postinfusion systemic reactions. No malignancies, opportunistic infections, or suicidality events were reported in the study. Clinical chemistry, hematology, liver function, and vital sign measurements revealed no findings of clinical relevance.

\section{Pharmacodynamic/biomarker results}

Two participants with MuSK antibodies were identified (placebo group); all other participants had $\mathrm{AChR}$ antibodies. A small decrease in AChR antibody titers occurred in both treatment groups during the treatment phase; these returned to baseline levels during follow-up (figure e-1A, links.lww. com/WNL/A370). No relationship was observed between efficacy and percentage change in antibody levels from baseline to week 24 (overall correlation coefficients: QMG -0.025; MGC -0.090) (figure e-1, B and C).

\section{Pharmacokinetics results}

Pharmacokinetic results are presented in table e-1 (links.lww. com/WNL/A371). Steady-state belimumab concentrations were reached early in the trial and maintained throughout the treatment period.

\section{Discussion}

This phase II study evaluated the efficacy and safety of belimumab in participants with generalized MG who remained symptomatic while on SoC therapy. The primary endpoint (mean change from baseline in the QMG score at week 24) was not met. Although the data showed a small numerical improvement in favor of belimumab, this was not statistically significant and the treatment difference of $\sim 2$ points was below that considered to be clinically meaningful (3-4 points). ${ }^{27}$ In this study, posterior probability analysis indicated a signal of potential efficacy (posterior probability $>0.8$ ). Further analysis of the QMG scale data showed that, while not statistically significant, a higher proportion of participants improved with belimumab treatment compared with placebo at week 24, and demonstrated sustained improvement from weeks $12-24$. This endpoint has been widely used in nonregulatory MG clinical trials and provides a validated measure of muscle strength. ${ }^{22,27}$

There was no difference between belimumab and placebo for mean change from baseline for MGC and MG-ADL (week 24 and 36). Mean change from baseline in QMG score, and the proportion of participants improving as measured by QMG, 
Table 2 Mixed model for repeated measures (MMRM) analysis of change from baseline in Quantitative Myasthenia Gravis (QMG), Myasthenia Gravis Composite (MGC), and Myasthenia Gravis Activities of Daily Living (MG-ADL) at weeks 24 and 36, and proportion of participants with improved, worsening, or sustained improvement in QMG/ MGC scores at week 24

Change from baseline in QMG, MGC, and MG-ADL

QMG, week 24 (ITT)

n

Adjusted mean (SE)

Difference of adjusted mean (SE; $95 \% \mathrm{Cl}^{p} p$ value) ${ }^{\mathrm{a}}$

QMG, week 24 (PP)$$
\text { n }
$$$$
\text { Adjusted mean (SE) }
$$

Difference of adjusted mean (SE; $95 \% \mathrm{Cl} p$ value) ${ }^{\mathrm{a}}$

QMG, week 36 (ITT)

n

Adjusted mean (SE)

Difference of adjusted mean (SE; $95 \% \mathrm{Cl} ; p$ value) ${ }^{a}$

MGC, week 24 (ITT)

n

Adjusted mean (SE)

Difference of adjusted mean (SE; $95 \% \mathrm{Cl} ; p$ value) ${ }^{a}$

MGC, week 36 (ITT)

$$
\text { n }
$$

Adjusted mean (SE)

Difference of adjusted mean (SE; $95 \% \mathrm{Cl} \boldsymbol{p}$ value) ${ }^{\mathrm{a}}$

MG-ADL, week 24, (ITT)

\begin{tabular}{|c|c|c|}
\hline $\mathbf{n}$ & 17 & 17 \\
\hline Adjusted mean (SE) & $-2.01(0.59)$ & $-2.32(0.60)$ \\
\hline Difference of adjusted mean (SE; $95 \% \mathrm{Cl} ; \boldsymbol{p}$ value) ${ }^{a}$ & - & $-0.31(0.84 ;-2.03,1.40 ; p=0.711)$ \\
\hline \multicolumn{3}{|l|}{ MG-ADL, week 36 (ITT) } \\
\hline $\mathbf{n}$ & 17 & 14 \\
\hline Adjusted mean (SE) & $-1.51(0.62)$ & $-1.78(0.66)$ \\
\hline Difference of adjusted mean (SE; $95 \% \mathrm{Cl} ; \boldsymbol{p}$ value) ${ }^{a}$ & - & $-0.26(0.91 ;-2.12,1.59 ; p=0.775)$ \\
\hline
\end{tabular}

Improved, worsening, or sustained improvement in QMG/MGC

QMG, week 24 (ITT)

Improvement ( $\geq 3$ points)

\begin{tabular}{lll}
\hline $\mathbf{n}(\%)^{c}$ & $6(29)$ & $11(61)$ \\
\hline $\mathbf{O R}^{\mathrm{d}}(\mathbf{9 5 \%} \mathrm{Cl} ; \boldsymbol{p}$ value) & - & $3.81(0.87,19.02 ; p=0.082)$ \\
\hline Worsening ( $\geq 3$ points) & & $2(11)$ \\
\hline $\mathbf{n}(\%)^{c}$ & $4(19)$ & \\
\hline
\end{tabular}

$n(\%)^{c}$
17

$-4.21(1.14)$

$-1.84(1.59 ;-5.08,1.40 ; p=0.256)$

12

$-5.20(1.51)$

$-2.36(2.07 ;-6.64,1.93 ; p=0.267)$

14

$-4.73(0.92)$

$-2.29(1.27 ;-4.88,0.30 ; p=0.081)$

17

$-3.81(1.06)$

$0.05(1.49 ;-2.97,3.07 ; p=0.972)$

- $0.05(1.49 ;-2.97,3.07 ; p=0.972)$

17

$-4.77(0.97) \quad-5.04(1.05)$

$-\quad-0.28(1.43 ;-3.21,2.65 ; p=0.848)$ 
Table 2 Mixed model for repeated measures (MMRM) analysis of change from baseline in Quantitative Myasthenia Gravis (QMG), Myasthenia Gravis Composite (MGC), and Myasthenia Gravis Activities of Daily Living (MG-ADL) at weeks 24 and 36, and proportion of participants with improved, worsening, or sustained improvement in QMG/MGC scores at week 24 (continued)

\begin{tabular}{|c|c|c|}
\hline Endpoint & Placebo $(n=21)$ & Belimumab $10 \mathrm{mg} / \mathrm{kg}(\mathrm{n}=18)$ \\
\hline $\mathrm{OR}^{\mathrm{d}}(95 \% \mathrm{Cl} ; \boldsymbol{p}$ value $)$ & - & $0.55(0.05,4.35 ; p=0.827)$ \\
\hline \multicolumn{3}{|l|}{ Sustained improvement ${ }^{\text {b }}$} \\
\hline$n(\%)^{c}$ & $5(24)$ & $8(44)$ \\
\hline $\mathrm{OR}^{\mathrm{d}}(95 \% \mathrm{Cl} ; \boldsymbol{p}$ value $)$ & - & $2.51(0.62,10.10 ; p=0.184)$ \\
\hline \multicolumn{3}{|l|}{ MGC, week 24 (ITT) } \\
\hline \multicolumn{3}{|l|}{ Improvement ( $\geq 3$ points) } \\
\hline$n(\%)^{c}$ & $10(48)$ & $9(50)$ \\
\hline $\mathrm{OR}^{\mathrm{d}}(95 \% \mathrm{Cl} ; \boldsymbol{p}$ value $)$ & - & $1.17(0.26,5.48 ; p=1.000)$ \\
\hline \multicolumn{3}{|l|}{ Worsening ( $\geq 3$ points) } \\
\hline$n(\%)^{c}$ & $5(24)$ & $2(11)$ \\
\hline $\mathrm{OR}^{\mathrm{d}}(95 \% \mathrm{Cl} ; \boldsymbol{p}$ value $)$ & - & $0.40(0.03,2.89 ; p=0.530)$ \\
\hline \multicolumn{3}{|l|}{ Sustained improvement ${ }^{b}$} \\
\hline$n(\%)^{c}$ & $4(19)$ & $7(39)$ \\
\hline $\mathrm{OR}^{\mathrm{d}}(95 \% \mathrm{Cl} ; \boldsymbol{p}$ value $)$ & - & $2.70(0.64,11.46 ; p=0.175)$ \\
\hline \multicolumn{3}{|c|}{$\begin{array}{l}\text { Abbreviations: } \mathrm{Cl}=\text { confidence interval; ITT = intention-to-treat; } \mathrm{OR}=\text { odds ratio; } \mathrm{PP}=\text { per protocol. } \\
\text { a The differences in adjusted least square means are presented (belimumab } 10 \mathrm{mg} / \mathrm{kg} \text { minus placebo). A negative treatment difference indicates benefit } \\
\text { relative to placebo. The analysis method was MMRM adjusted for treatment, visit, baseline score, treatment by visit, and baseline score by visit; the QMG score } \\
\text { at baseline is the average of the screening and week } 0 \text { baseline scores. } \\
\text { b Sustained improvement = improvement in QMG/MGC score of } \geq 3 \text { points from baseline at week } 12 \text {, and the participant maintaining this improvement } \\
\text { through to week } 24 \text {. } \\
\text { c Proportions compared using exact analyses stratified by the observed median baseline score ( } \leq \text { median, > median). } \\
\text { d Exact OR, double the exact one-sided } p \text { values, and exact Cls are presented; ORs are calculated using Cochran-Mantel-Haenszel method with no adjustment } \\
\text { for strata. Wald Cls are presented. }\end{array}$} \\
\hline
\end{tabular}

demonstrated a slight numerical improvement over placebo. Overall, the QMG, MGC, and MG-ADL scales all indicated a lack of belimumab effect. The MGC, a validated MG rating scale recommended by the MGFA taskforce, ${ }^{28}$ differs from the QMG in 2 key aspects: (1) it is a weighted scale where symptoms considered to have a greater effect on the patient are given a higher score; (2) it takes into account the patient's own view of his or her symptoms. The QMG, by contrast, is entirely physician-assessed and scores all symptoms on the same scale ${ }^{22}$; such differences may explain the slight improvement observed in the QMG score compared with either MGC or MG-ADL.

Belimumab serum concentrations were as expected based on prior clinical experience in 2 phase III registration studies in SLE. ${ }^{29}$ Decreased naive B-cell and increased memory B-cell counts were seen following belimumab treatment; given the inhibitory effect of belimumab on B cells, this was not unexpected and has previously been reported in SLE. ${ }^{9}$ No correlation between efficacy (QMG or MGC) and change in antibody levels was seen. Longer periods of time may be required to observe alterations in antibody level; some autoantibodies require 1-2 years of belimumab treatment to be significantly reduced. ${ }^{30}$ In addition, peripheral antibody titers may not be a valid marker of the neuromuscular junction process. This lack of correlation is consistent with previous observations in $\mathrm{MG}^{27,31}$

The safety profile for belimumab was consistent with that seen in SLE studies; no new safety signals were identified in this generalized MG population and only one death was reported (placebo group). ${ }^{18,32}$

This study has several limitations. Participants recruited were already receiving SoC therapy. The mild level of severity in the population studied here may have contributed to scale insensitivity and floor effects (i.e., the lower limits of the QMG scale were higher than the corresponding disease severity). Participants recruited for the current study may have achieved a symptom plateau, thus reducing the likelihood of further improvement with belimumab. A prior study of patients with more severe MG (QMG baseline score of $\geq 12$ ) did identify a response to eculizumab treatment. ${ }^{17}$ The inclusion of participants with more severe MG may have resulted in an improved outcome. Lack of MuSK participants may have contributed to the lack of efficacy. Indeed, case studies with B-cell-targeting rituximab have reported 
Table 3 Participants reporting adverse events (AEs) during the study (safety population)

\begin{tabular}{lll}
\hline \multicolumn{1}{l}{} & Placebo $(\mathbf{n = 2 2})$ & Belimumab 10 $\mathbf{m g} / \mathbf{k g}(\mathbf{n}=\mathbf{1 8})$ \\
\hline Participants reporting AEs during the treatment phase, $\mathbf{n}(\%)$ & $20(91)$ & $14(78)$ \\
\hline Total AEs & $7(32)$ & $5(28)$ \\
\hline AEs related to study treatment & $3(14)$ & 0 \\
\hline AEs leading to discontinuation & $5(23)$ & $4(22)$ \\
\hline AESI & $2(9)$ & $2(11)$ \\
\hline Postinfusion systemic reactions & $1(5)$ & $1(6)$ \\
\hline All infections of special interest & $2(9)$ & $1(6)$ \\
\hline Depression/suicide/self-injury & $4(18)$ & 0 \\
\hline SAE & $5(23)$ & $1(6)$ \\
\hline Severe AE & $1(5)$ & 0
\end{tabular}

Most common AEs (occurring in $\geq 3$ participants in any group during the treatment phase), $\mathrm{n}(\%)$

\begin{tabular}{lll}
\hline Influenza & 0 & $3(17)$ \\
\hline Nausea & 0 & $3(17)$ \\
\hline Diarrhea & $4(18)$ & $1(6)$ \\
\hline Headache & $3(14)$ & 0 \\
\hline Back pain & $3(14)$ & $12(67)$ \\
\hline Participants reporting AEs during the follow-up phase, $\mathbf{n}(\%)$ & $12(55)$ & $2(11)$ \\
\hline Total AEs & $1(5)$ & - \\
\hline AEs related to study treatment & - & 0 \\
\hline AESI & 0 & 0 \\
\hline All infections of special interest & 0 & 0 \\
\hline Depression/suicide/self-injury & 0 & $3(17)$ \\
\hline SAEs & $1(5)$ & 0 \\
\hline Severe AEs & 0 & 0 \\
\hline Deaths & & \\
\hline
\end{tabular}

Abbreviations: AESI = adverse events of special interest; SAE = serious adverse events.

improved and longer-lasting clinical benefit in patients with MuSK MG than those with AChR antibodies. ${ }^{15}$ Finally, this was a small study $(\mathrm{n}=40)$; as such, considerable variability in the dataset may be expected, with small participant numbers driving the observations seen.

Several emerging therapies for MG have shown promising results. Rituximab, which targets $B$ cells, albeit differently from belimumab, has demonstrated improved clinical outcomes and reduced immunotherapy requirements in a number of retrospective case studies of MG. ${ }^{14-16,33,34}$ No published, adequately powered, randomized, controlled trials of rituximab in MG currently exist. Eculizumab, a humanized monoclonal antibody that blocks complement activation, has shown significant clinical benefit for the improvement of MG compared with placebo in a small $(\mathrm{n}=14)$ randomized phase II study. ${ }^{17}$ In a larger $(n=125)$ phase III study of patients with an MG-ADL total score $\geq 6$ who had previously failed treatment, the primary endpoint, change in MG-ADL, did not reach statistical significance. Statistical significance was achieved for several prespecified analyses. ${ }^{35}$

This study did not meet its primary endpoint and belimumab demonstrated no significant efficacy compared with placebo in participants with generalized MG who were receiving SoC treatments. 


\section{Author contributions}

Study conception or design: K.H., R.A.G., C.L.B., D.B.S. Acquisition of data: V.B. Data analysis or interpretation: K.H., R.A.G., C.L.B., M.Z.-H., T.J.R., A.B.

\section{Acknowledgment}

The authors thank Dr. Kevan VanLandingham (GSK at time of study), Dr. April Thompson (GSK), and Mieke Jobsis (GSK) for contributions to the study; Professor Angela Vincent and Dr. Leslie Jacobson (Nuffield Department of Clinical Neurosciences, University of Oxford, UK) for performing the antibody analysis; and Sam Halliwell, $\mathrm{PhD}$, and Jennie McLean, PhD, of Fishawack Indicia Ltd, UK, for medical writing support, which was funded by GSK, but did not contribute to the study design or acquisition, analysis, or interpretation of data.

\section{Study funding}

This study was funded by GlaxoSmithKline (study number BEL115123).

\section{Disclosure}

$\mathrm{K}$. Hewett is an employee of GSK and holds shares in the company. D. Sanders: consultant to GSK, UCB, Accordant Health Services, and Jacobus Pharmaceutical Co. R. Grove is an employee of GSK and holds shares in the company. C. Boderick is an employee of GSK and holds shares in the company. T. Rudo is an employee of GSK and holds shares in the company. A. Bassiri is an employee of GSK and holds shares in the company. M. Zvartau-Hind is an employee of GSK and holds shares in the company. V. Bril: consultant to Bionevia, CSL Behring, UCB, Grifols, Octapharma, Argenx, and Alpha Cancer Technologies, and research funding from CSL Behring, UCB, Grifols, Octapharma, and Argenx. Go to Neurology.org/N for full disclosures.

Received April 26, 2017. Accepted in final form January 17, 2018.

\section{References}

1. Melzer N, Ruck T, Fuhr P, et al. Clinical features, pathogenesis, and treatment of myasthenia gravis: a supplement to the Guidelines of the German Neurological Society. J Neurol 2016;263:1473-1494.

2. Sanders DB, Wolfe GI, Benatar M, et al. International consensus guidance for management of myasthenia gravis: executive summary. Neurology 2016;87:419-425.

3. Hart IK, Sathasivam S, Sharshar T. Immunosuppressive agents for myasthenia gravis. Cochrane Database Syst Rev 2007;4:CD005224.

4. El-Salem K, Yassin A, Al-Hayk K, Yahya S, Al-Shorafat D, Dahbour SS. Treatment of MuSK-associated myasthenia gravis. Curr Treat Options Neurol 2014;16:283.

5. Cordts I, Bodart N, Hartmann K, et al. Screening for lipoprotein receptor-related protein 4-, agrin-, and titin-antibodies and exploring the autoimmune spectrum in myasthenia gravis. J Neurol 2017:1-11.

6. Shen C, Lu Y, Zhang B, et al. Antibodies against low-density lipoprotein receptorrelated protein 4 induce myasthenia gravis. J Clin Invest 2013;123:5190.
7. Sanders DB, Evoli A. Immunosuppressive therapies in myasthenia gravis. Autoimmunity 2010;43:428-435.

8. Phillips WD, Vincent A. Pathogenesis of myasthenia gravis: update on disease types, models and mechanisms F1000res 2016;5:F1000.

9. Baker $\mathrm{KP}$, Edwards $\mathrm{BM}$, Main $\mathrm{SH}$, et al. Generation and characterization of LymphoStat-B, a human monoclonal antibody that antagonizes the bioactivities of B lymphocyte stimulator. Arthritis Rheum 2003;48:3253-3265.

10. GSK. Benlysta-pi-mg full prescribing information. Brentford, UK: GSK; 2015.

11. Lisak RP, Ragheb S. The role of B cell-activating factor in autoimmune myasthenia gravis. Ann NY Acad Sci 2012;1274:60-67.

12. Kim JY, Yang Y, Moon JS, et al. Serum BAFF expression in patients with myasthenia gravis. J Neuroimmunol 2008;199:151-154.

13. Scuderi F, Alboini PE, Bartoccioni E, Evoli A. BAFF serum levels in myasthenia gravis: effects of therapy. J Neurol 2011;258:2284-2285.

14. Anderson D, Phan C, Johnston WS, Siddiqi ZA. Rituximab in refractory myasthenia gravis: a prospective, open-label study with long-term follow-up. Ann Clin Transl Neurol 2016;3:552-555.

15. Diaz-Manera J, Martinez-Hernandez E, Querol L, et al. Long-lasting treatment effect of rituximab in MuSK myasthenia. Neurology 2012;78:189-193.

16. Iorio R, Damato V, Alboini PE, Evoli A. Efficacy and safety of rituximab for myasthenia gravis: a systematic review and meta-analysis. J Neurol 2015;262:1115-1119.

17. Howard JF, Barohn RJ, Cutter GR, et al. A randomized, double-blind, placebocontrolled phase II study of eculizumab in patients with refractory generalized myasthenia gravis. Muscle Nerve 2013;48:76-84.

18. Furie R, Petri M, Zamani O, et al. A phase III, randomized, placebo-controlled study of belimumab, a monoclonal antibody that inhibits B lymphocyte stimulator, in patients with systemic lupus erythematosus. Arthritis Rheum 2011;63: 3918-3930.

19. Navarra SV, Guzmán RM, Gallacher AE, et al. Efficacy and safety of belimumab in patients with active systemic lupus erythematosus: a randomised, placebo-controlled, phase 3 trial. Lancet 2011;377:721-731.

20. World Medical Association. World Medical Association Declaration of Helsinki: ethical principles for medical research involving human subjects. JAMA 2013;310: 2191-2194.

21. Jaretzki A, Barohn R, Ernstoff R, et al. Myasthenia gravis recommendations for clinical research standards. Neurology 2000;55:16-23.

22. Barohn RJ, McIntire D, Herbelin L, Wolfe GI, Nations S, Bryan WW. Reliability testing of the Quantitative Myasthenia Gravis score. Ann NY Acad Sci 1998;841: 769-772.

23. Burns TM, Conaway M, Sanders DB. The MG Composite: a valid and reliable outcome measure for myasthenia gravis. Neurology 2010;74:1434-1440.

24. Wolfe G, Herbelin L, Nations S, Foster B, Bryan W, Barohn R. Myasthenia gravis activities of daily living profile. Neurology 1999;52:1487-1489.

25. Lane P. Handling drop-out in longitudinal clinical trials: a comparison of the LOCF and MMRM approaches. Pharm Stat 2008;7:93-106.

26. Berry DA. Bayesian clinical trials. Nat Rev Drug Discov 2006;5:27-36.

27. Barnett C, Katzberg H, Nabavi M, Bril V. The Quantitative Myasthenia Gravis score: comparison with clinical, electrophysiological, and laboratory markers. J Clin Neuromuscul Dis 2012;13:201-205.

28. Benatar M, Sanders DB, Burns TM, et al. Recommendations for myasthenia gravis clinical trials. Muscle Nerve 2012;45:909-917.

29. Struemper H, Chen C, Cai W. Population pharmacokinetics of belimumab following intravenous administration in patients with systemic lupus erythematosus. J Clin Pharmacol 2013;53:711-720.

30. Ginzler EM, Wallace DJ, Merrill JT, et al. Disease control and safety of belimumab plus standard therapy over 7 years in patients with systemic lupus erythematosus. J Rheumatol 2014;41:300-309.

31. Sanders DB, Burns TM, Cutter GR, Massey JM, Juel VC, Hobson-Webb L. Does change in acetylcholine receptor antibody level correlate with clinical change in myasthenia gravis? Muscle Nerve 2014;49:483-486.

32. Wallace DJ, Stohl W, Furie RA, et al. A phase II, randomized, double-blind, placebocontrolled, dose-ranging study of belimumab in patients with active systemic lupus erythematosus. Arthritis Rheum 2009;61:1168-1178.

33. Sieb J. Myasthenia gravis: an update for the clinician. Clin Exp Immunol 2014;175: 408-418.

34. Tandan R, Hehir MK, Waheed W, Howard DB. Rituximab treatment of myasthenia gravis: a systematic review. Muscle Nerve 2017;56:185-196.

35. Howard J. REGAIN: a randomized, double-blind, placebo-controlled multi-center phase 3 study of the safety and efficacy of eculizumab in subjects with refractory generalized myasthenia gravis. Presented at the 14th International Congress on Neuromuscular Diseases (ICNMD); July 7, 2016; Toronto. 


\section{Randomized study of adjunctive belimumab in participants with generalized myasthenia gravis}

Karen Hewett, PhD, Donald B. Sanders, MD, Richard A. Grove, MSc, Christine L. Broderick, BS, Todd J. Rudo, MD, Ashlyn Bassiri, PhD, Marina Zvartau-Hind, MD, and Vera Bril, MD, On behalf of the BEL115123 Study Group
Correspondence

Prof. Bril

vera.bril@utoronto.ca

Cite as: Neurology ${ }^{\circledR}$ 2018;90:e1425-e1434. doi:10.1212/WNL.0000000000005323

\section{Trial registration number}

NCT01480596 on ClinicalTrials.gov.

\section{Study question}

Can belimumab reduce the severity of generalized myasthenia gravis (MG) in patients who remain symptomatic despite standard of care (SoC) therapy?

\section{Summary answer}

Belimumab did not significantly improve the symptoms of MG compared with placebo.

\section{Classification of evidence \\ Class I.}

\section{What is known and what this paper adds}

Belimumab is a monoclonal antibody targeting B-lymphocyte stimulator, levels of which are elevated in patients with MG. Other monoclonal antibodies targeting immune elements have shown promise in MG. This study does not provide evidence for belimumab's efficacy.

\section{Participants and setting}

This study enrolled 40 adults with MG (women, $62 \%$; mean age, 56.1 [SD \pm 15.67 years]) who expressed acetylcholine receptor or muscle-specific kinase antibodies, and had baseline quantitative $M G$ ( $Q M G)$ scores $\geq 8$, including $\geq 4$ points from non-ocular signs. The study was conducted at 13 Canadian, US, German, and Italian centers between April 2013 and October 2015. Exclusion criteria included pregnancy, history of thymoma, and receipt of rituximab or eculizumab (past 12 months) or another B cell-targeting therapy (at any point).

\section{Design, size, and duration}

This phase II, double-blind, placebo-controlled study used a computer-generated randomization schedule with stratification by antibody status to assign participants to either placebo $(\mathrm{n}=22)$ or belimumab $(\mathrm{n}=18)$. IV belimumab $(10 \mathrm{mg} / \mathrm{kg})$ was administered at Weeks 0, 2, 4, 8, 12, 16, and 20. All participants received SoC therapy throughout the study.

\section{Primary outcomes}

The primary outcome was change from baseline in QMG score at Week 24.
Figure Adjusted mean change from baseline in QMG score (MMRM)

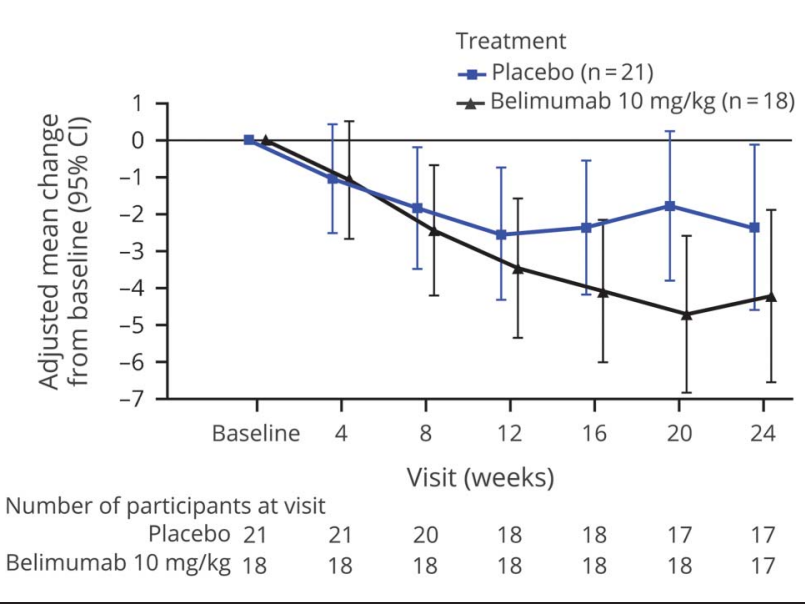

\section{Main results and the role of chance}

Change in QMG score from baseline (Week 24) in the belimumab group was comparable to the placebo group $(-4.21$ $[\mathrm{SE} \pm 1.14]$ vs 2.37 [SE \pm 1.10$]$, respectively; $p=0.256$ ).

\section{Harms}

Adverse events were reported to a similar extent in the belimumab and placebo groups ( $78 \%$ vs $91 \%$, respectively). No new safety signals were identified.

Bias, confounding, and other reasons for caution This study had a relatively small sample size. The inclusion of mild cases might have obscured belimumab's effects.

\section{Generalizability to other populations}

The participants had relatively mild cases of MG. This may limit the generalizability of the results to severe cases.

\section{Study funding/potential competing interests}

This study was funded by GlaxoSmithKline. Some authors are employees of and shareholders in GlaxoSmithKline. Some authors report consulting for and receiving funding from various pharmaceutical companies including GlaxoSmithKline. Go to Neurology.org/N for full disclosures. 


\section{Neurology}

\section{Randomized study of adjunctive belimumab in participants with generalized myasthenia gravis}

Karen Hewett, Donald B. Sanders, Richard A. Grove, et al.

Neurology 2018;90;e1425-e1434 Published Online before print March 21, 2018

DOI 10.1212/WNL.0000000000005323

\section{This information is current as of March 21, 2018}

\section{Updated Information \& Services}

References

Citations

Subspecialty Collections

Permissions \& Licensing

Reprints including high resolution figures, can be found at: http://n.neurology.org/content/90/16/e1425.full

This article cites 32 articles, 5 of which you can access for free at: http://n.neurology.org/content/90/16/e1425.full\#ref-list-1

This article has been cited by 1 HighWire-hosted articles: http://n.neurology.org/content/90/16/e1425.full\#\#otherarticles

This article, along with others on similar topics, appears in the following collection(s):

\section{All Neuromuscular Disease}

http://n.neurology.org/cgi/collection/all_neuromuscular_disease

Autonomic diseases

http://n.neurology.org/cgi/collection/autonomic_diseases

Class I

http://n.neurology.org/cgi/collection/class_1

Clinical trials Randomized controlled ( $\overline{\mathbf{C} O N S O R T}$ agreement)

http://n.neurology.org/cgi/collection/clinical_trials_randomized_contro

lled_consort_agreement

Myasthenia

http://n.neurology.org/cgi/collection/myasthenia

Information about reproducing this article in parts (figures,tables) or in its entirety can be found online at:

http://www.neurology.org/about/about_the_journal\#permissions

Information about ordering reprints can be found online:

http://n.neurology.org/subscribers/advertise

Neurology ${ }^{\circledR}$ is the official journal of the American Academy of Neurology. Published continuously since 1951, it is now a weekly with 48 issues per year. Copyright Copyright ( 2018 The Author(s). Published by Wolters Kluwer Health, Inc. on behalf of the American Academy of Neurology.. All rights reserved. Print ISSN: 0028-3878. Online ISSN: 1526-632X.

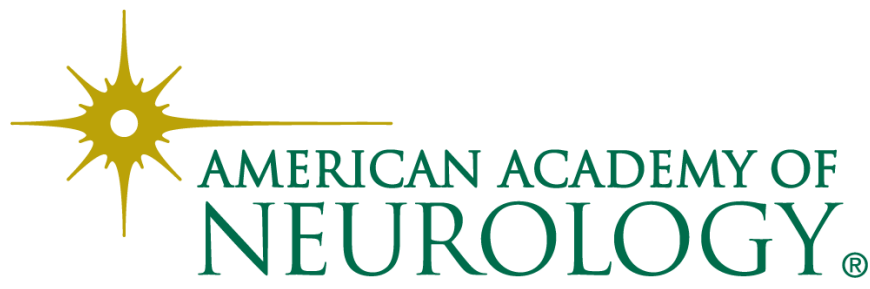

